Preference is given to letters commenting on contributions published recently in the JRSM. They should not exceed 300 words and should be typed double spaced

\section{Thyroid function in chronic urticaria and angio-oedema}

In a case report (August 2003, $J R S M^{1}$ ) Dr Edwards and colleagues discuss the relation between subacute thyroiditis and chronic urticaria and angio-oedema (CUA). ${ }^{1}$ Here we describe a case that illustrates the possible role of thyroxine in suppressing CUA, as previously postulated.

A woman of 52 was seen at another department in August 2002 with widespread arthralgia (large joints), shoulder girdle stiffness and early morning stiffness. In September 2002 she also noticed dry eyes and mouth, associated with sweatiness. Her previous history included CUA diagnosed in 1988, and hypothyroidism requiring thyroxine $150 \mu \mathrm{g}$ daily since the age of 17 . Her menstrual periods had stopped eleven months earlier. The relevant findings were: Schirmer's tear test normal (wet); erythrocyte sedimentation rate $22 \mathrm{~mm} / \mathrm{h}$, C-reactive protein $11 \mathrm{mg} / \mathrm{L}$, autoimmune screen negative, alkaline phosphatase $136 \mathrm{U} / \mathrm{L}$ (normal 39-117), TSH $<0.06 \mathrm{mU} / \mathrm{L}$ (0.5-4.7), $\mathrm{fT}_{4} 28.3 \mathrm{pmol} / \mathrm{L}(9.1-23.9), \mathrm{fT}_{3} 1.91 \mathrm{nmol} / \mathrm{L}$ (1.20-2.20). She was started on prednisolone $5 \mathrm{mg}$ twice daily and diclofenac/misoprostol $50 \mathrm{mg} / 200 \mathrm{mg}$ twice daily in October 2002 for a presumed inflammatory musculoskeletal condition. On review in February 2003 her symptoms had not resolved. Thyroid peroxidase antibodies were absent. As the TSH was persistently suppressed $(<0.01 \mathrm{mU} / \mathrm{L})$ and $\mathrm{fT}_{4}$ was raised $(18-30 \mathrm{pmol} / \mathrm{L})$, the thyroxine dose was reduced from $150 \mu \mathrm{g}$ to $125 \mu \mathrm{g}$ daily in February, then to $100 \mu \mathrm{g}$ in April and $75 \mu \mathrm{g}$ in May 2003. The prednisolone dose was also reduced every 2-3 weeks by $1 \mathrm{mg} /$ day between March and May to a maintenance dose of $5 \mathrm{mg} /$ day.

In late April, having been urticaria-free for 15 years, the patient developed generalized urticaria and angio-oedema which persisted for 6 weeks and required antihistamine treatment. There was a further episode of CUA in June.

The dose of diclofenac/misoprostol was not changed from October 2002 until May 2003 when it was stopped because of an abnormal liver function test. At the time of writing (September) the patient has had no further episodes of urticaria/angio-oedema and her daily dose of thyroxine has been $75 \mu \mathrm{g}$ since mid-May. Current TSH is $2.0 \mathrm{mU} / \mathrm{L}$, $\mathrm{fT}_{4} 16.4 \mathrm{pmol} / \mathrm{L}$.

We propose that this patient's flare of CUA was related to the reduction in thyroxine dose. Previously the condition may have been suppressed by the excessive dosage. However, we cannot exclude the possibility that the reduction of her prednisolone dose was an aetiological factor, though this was very gradual. Furthermore, the treatment with diclofenac, well known to precipitate urticaria, may be relevant - though she took this drug for seven months before the return of CUA and had not taken it for 4 weeks before the second episode.

If we postulate that each reduction in thyroxine dose is followed by a 3-4 week latent period before reactivation of CUA, then the final episode of urticaria in June could be explained by the dosage alteration in May, and the April/ May flare by the dosage alteration in mid-March and early April. The possible role of thyroxine in suppressing CUA requires further investigation.

\section{Dunkley}

A S M Jawad

Rheumatology Department, Royal London Hospital, Bancroft Road, London E1 4DG, UK

E-mail: alismjawad1@hotmail.com

\section{REFERENCES}

1 Edwards CMB, Cream JJ, Cassar J. Swollen lips and a tender neck. J R Soc Med 2003;96:402-3

2 Zauli D, Grassi A, Ballardini G, Contestabile S, Zucchini S, Bianchi FB. Thyroid autoimmunity in chronic idiopathic urticaria: implications for therapy. Am J Clin Dermatol 2002;3:525-8

\section{Jumperphagia: a woolly diagnosis}

Last year in the JRSM, Woywodt and Kiss recorded the history of earth-eating, ${ }^{1}$ and Grewal and Fitzgerald ${ }^{2}$ described the case of a learning-disabled man who consumed metal objects and pieces of clothing. Some workers hypothesize that such habits (pica) are related to dietary deficiencies. Here we report some evidence in support.

A woman of 67 was being investigated for longstanding iron deficiency. Upper gastrointestinal endoscopy had been negative, but on colonoscopy the bowel contained several clumps of what appeared to be fabric. A dietary history, taken thereafter, revealed that she was in the habit of consuming whole woollen jumpers at a single sitting; also her iron intake was low. After iron supplementation and nutritional advice, both her urge to eat wool and the anaemia gradually resolved.

Pica has been linked with severe iron-deficiency anaemia in children ${ }^{3}$ and adults. ${ }^{4}$ The question of cause and effect has not been resolved. In the past the habit has been seen as a manifestation of other disorders rather than an entity. ${ }^{5,6}$ Here, cessation of pica after successful treatment of the anaemia indicates that iron deficiency might have contributed to the causation.

\section{Guy Nash}

Rachel Evans

Richard Cohen

St Mark's Hospital, Harrow HA1 3UK, UK 


\section{REFERENCES}

1 Woywodt A, Kiss A. Geophagia: the history of earth-eating. J R Soc Med 2002;9:143-6

2 Grewal P, Fitzgerald B. Pica with learning disability. J R Soc Med 2002;95:39-40

3 Saloojee H, Pettifor J. Iron deficiency and impaired child development: the relation may be causal, but it may not be a priority for intervention. BMJ 2001;323:1377-8

4 Anderson JE, Akmal M, Kittur DS. Surgical complications of pica: report of a case of intestinal obstruction and a review of the literature. Am Surg 1991;57:663-7

5 Parry-Jones B, Parry-Jones WL. Pica: symptom or eating disorder? A historical assessment. BrJ Psychiatry 1992;160:341-4

6 McLoughlin IJ. The picas. Br J Hosp Med 1987;37:286-90

\section{Patients' understanding of anticoagulant therapy}

The paper by Dr Nadar and co-workers (April 2003 JRSM ${ }^{1}$ ) pointed out gaps in knowledge about antithrombotic therapy of anticoagulated patients from ethnic minorities in Birmingham. It also indicated that being over 61 years is associated with a low knowledge score. Attempts are made in our monitoring service to inform patients about their warfarin therapy, but only by providing new patients with written information and continuing opportunities to have their questions addressed.

We set out to determine the satisfaction of anticoagulated patients with the information with which they had been provided and whether their level of knowledge was influenced by age, length of treatment and indication for warfarin therapy. 57 consecutive patients, 26 under 65 years and 31 of 65 years and over, all white European, attending the anticoagulant clinic at the Royal Victoria Infirmary, Newcastle upon Tyne, consented to complete the study questionnaire, administered by HL who is not a member of the clinic staff. The study had Newcastle upon Tyne Joint Ethics Committee approval. All 57 patients reported having received adequate information about warfarin. $26(84 \%)$ patients of 65 years and over had no concerns about bleeding compared with $12(46 \%)$ under 65 years. Only $8(26 \%)$ of those of 65 years and over knew about the potential of antibiotics to increase the international normalized ratio (INR), and 11 (35\%) were aware of alcohol's potential to increase it; none knew that green vegetables could reduce it. This compared with, for those under 65 years, $12(46 \%)$ knowing of the interaction with antibiotics $(P<0.01$, risk ratio (rr) $1.51,95 \% \mathrm{CI}$ $1.15-1.98), 23(88 \%)$ of the interaction with alcohol $(P<0.0001 ;$ rr $2.51 ; 95 \%$ CI $1.94-3.36)$, and $3(12 \%)$ of the interaction with green vegetables $\left(\chi^{2}\right.$ for trend in mean score, $P<0.0001)$. It was only for potential interactions between warfarin and antibiotics that knowledge was better those anticoagulated for less than this time $(P<0.0001$; rr $0.48 ; 95 \%$ CI $0.32-0.72$ ). The indication for warfarin had no apparent influence upon response.

Although as in Birmingham most patients expressed satisfaction with the information they had received, there are gaps in their knowledge. We support the call of Nadar and co-workers for more investment in patient education. Further investigation to determine the most effective means of informing patients about anticoagulation, with emphasis on high-risk subgroups which include not only ethnic minorities but also older people, and the effect of these interventions upon outcomes of therapy, is required.

\section{Hannah Lambert \\ Hilary Wynne ${ }^{1}$ \\ Medical School and ${ }^{1}$ Royal Victoria Infirmary, \\ Newcastle upon Tyne NE1 4LP, UK \\ e-mail: H.A.Wynne@nci.ac.uk}

\section{REFERENCE}

1 Nadar S, Begum N, Kaur B, Sandhu S, Lip GYH. Patients' understanding of anticoagulant therapy in a multiethnic population. $J R$ Soc Med 2003;96:175-9

\section{Cerebrovascular disease in The Count of Monte Cristo}

Dr Williams has written a most interesting analysis of cerebrovascular disease as depicted in Dumas' The Count of Monte Cristo (August 2003, JRSM $M^{1}$ ). In the case of Abbé Faria, Dumas portrays an old man who had three successive episodes of cerebral apoplexy with effusion that resulted in hemiplegia, probably referring to intracerebral haemorrhages, the last of which was fatal. Faria's father had died in exactly the same way after three episodes of cerebral apoplexy. Dr Williams mentions Osler-RenduWeber syndrome and Sturge-Weber syndrome as inheritable causes of recurrent cerebral haemorrhage. I would like to suggest adding cerebral amyloid angiopathy to that differential diagnosis since it is an autosomal dominant hereditary cause of recurrent lobar cerebral haemorrhage.

\section{James Goodwin}

Neuro-Ophthalmology Service, University of Illinois Eye \& Ear Infirmary, Chicago, Illinois b0612, USA

E-mail: jamegood@uic.edu

\section{REFERENCE}

1 Williams AN. Cerebrovascular disease in Dumas' The Count of Monte Cristo. J R Soc Med 2003;96:412-14 


\section{Periorbital cellulitis with breast cancer}

Dr Stevens and his colleagues (June 2003, JRSM ${ }^{1}$ ) describe a complex case in which periorbital cellulitis led to diagnosis of breast cancer metastasis to the sphenoid bone and the orbit. In our opinion, the periorbital cellulitis with which the patient presented might not have been due to the metastatic tumour. The CT scan shows opacity of the ethmoid sinuses bilaterally and of the right sphenoid sinus. The patient initially had pyrexia, periorbital swelling and erythema extending to the left side of her face - a clinical picture that together with the CT scan is strongly suggestive of periorbital cellulitis due to sinusitis. The sphenoid metastasis is indeed unusual and interesting but the reason she originally came to hospital may have been ethmoid sinusitis leading to periorbital cellulitis.

\section{Catherine Spinou}

\section{G W McGarry}

ENT Department, Queen Elizabeth Building, Glasgow Royal Infirmary, Glasgow G31 2ER, UK

\section{REFERENCE}

1 Stevens RJG, Rusby JE, Graham MD. Periorbital cellulitis with breast cancer. J R Soc Med 2003;96:292-4

\section{Legal considerations of clinical guidelines}

I agree with Dr Walden (September 2003, JRSM ${ }^{1}$ ) that clinical guidelines carry legal dangers.

Many groups, nowadays, produce guidelines on some subject with the best of intentions, to help newcomers. In my opinion, however, they are making a stick for lawyers to beat them with. At present, in the witness box, it is fair practice to pit one's experience against the expert on the other side. With guidelines available, any decent lawyer will be able to wave them aloft like an Act of Parliament, claiming that the whole of the group supports their findings and one member should never be able to disagree. Perhaps the word guidelines could be changed to something of a more advisory nature.

\section{Ivor E Doney}

3 Wallcroft, Durdham Park, Bristol BS6 6XJ, UK

\section{REFERENCE}

1 Walden RJ. Legal considerations of clinical guidelines. J R Soc Med 2003;96:412-13

\section{Complementary evidence}

In her discussion on evidence in complementary medicine (September 2003, $J R S M^{1}$ ) Professor Higginson makes the point that patients consult complementary therapists 'whose effectiveness, though not proven, is also not disproven, offering new hope when the "magic" of conventional medicine has faded'. Is she implying that it is all right to integrate unproven/not disproven therapies into routine healthcare as long as they offer hope? These are, of course, complex issues. It is nevertheless worth pointing out that, in certain circumstances, raising false hopes can be cruel and unethical. We should also remember that science cannot usually prove a negative. Thus, conclusively proving that homeopathy, spiritual healing, etc are ineffective (i.e. generate no effects beyond placebo) is an impossibility. This is why, in evidence-based medicine, treatments ought to be backed up by positive evidence of effectiveness rather than with a label of 'not disproven'. We all know that absence of evidence is not the same as evidence of absence. However, to use this argument for integrating therapies that are not disproven (basically anything from bloodletting to gene therapy) into medical routine is tantamount to saying 'anything goes'. If we take this stance in complementary medicine we must also take it in other areas of therapeutics. Imagine what this would mean in relation to the pharmaceutical industry.

I am sure that Professor Higginson did not mean to advocate any of this but we need to be aware of the indisputable reality that the integration of nonsense into routine healthcare is likely to result in nonsense. Therefore, I believe, the way forward in complementary medicine is not much different from that in any other area of healthcare: first conduct the research to test the value (effectiveness and safety) of an intervention; subsequently critically evaluate the data in the context of all the existing evidence, and finally, if the results are favourable, consider integration. To do it the other way round is, in my view, a disservice to everyone involved, not least the patient.

\section{E Ernst}

Complementary Medicine, Peninsula Medical School, Exeter, UK

E-mail: Edzard.Ernst@pms.ac.uk

\section{REFERENCE}

1 Higginson IJ. Complementary evidence? J R Soc Med 2003;96:427-8

\section{Medicolegal conferencing}

I was intrigued by Mr Pringle's excellent article (September 2003, $J R S M^{1}$ ). I published on the same subject in $2001^{2}$ and nothing has changed in the past two years. The defects in the arrangements for expert discussion will continue until changes are made in the current system of medical litigation. I will emphasize three matters. 
The Civil Procedure Rules make it clear that the discussion must be between like disciplines. Experts should make this clear to the judge issuing the order, and if necessary refuse to comply.

The second matter concerns whether or not one or both experts have conducted a recent examination and report. If not, discussion cannot take place and the judge managing the case must be so informed.

Thirdly, I think the judge, having read the reports, should set the agenda questions for the experts uninfluenced by instructing solicitors, but allowing the experts to raise any other matters.

\section{N H Harris}

72 Harley Street, London W1G 7HG, UK

REFERENCES

1 Pringle RG. An audit of medicolegal conferencing. $J$ R Soc Med 2003;96:454-7

2 Harris NH. Discussion between experts - a 21/2-year experience. Medical Litigation 2001;Dec: 10

\section{CORRECTION}

Tripling of blood pressure by sexual stimulation in a man with spinal cord injury

This case report (July $2003 J R S M^{1}$ ) states that autonomic dysreflexia occurs with spinal cord injury above the level of C6. This should have read T6. We apologize for this error, which was not the fault of the authors.

\section{REFERENCE}

1 McBride F, Quah SP, Scott ME, Dinsmore WW. Tripling of blood pressure by sexual stimulation in a man with spinal cord injury. J R Soc Med 2003;96:349-50 